\title{
Effect of Pulsed Electric Field on Alkaloids of Vinca rosea Root
}

\author{
S. Poompavai ${ }^{1}$, V. Gowri Sree ${ }^{1}$, Raji Sundararajan*2 \\ Department of Electrical and Electronics Engineering, College of Engineering, Anna University, Chennai, India. \\ School of Engineering Technology, West Lafayette, USA. \\ rsundara@purdue.edu \\ *Corresponding Author: Dr. Raji Sundararajan, School of Engineering Technology, West Lafayette, USA.
}

\begin{abstract}
Worldwide about 400 million people suffer from diabetes. It is a complex, systemic disease affecting many in both developed and developing countries. Treating this pandemic with costly synthetic drugs leads to several side effects and incomplete cure urges to give more importance to phytomedicines. From the very dawn, many bioactive compounds derived from medicinal plants have been used to treat human diseases. Most prevalent phytochemicals include alkaloids, polysaccharides, and phenols. Out of these, Vinca alkaloids, derived from Catharanthusroseus plant shows potent hypoglycaemic activity. A number of studies have been carried out to produce effective crude extracts from medicinal plants. Pulsed Electric Field (PEF) is an emerging non-thermal process which helps in enhancing the extraction process. In this study, the crude extract of roots of Vinca rosea, obtained by conventional method and with the pulsed electric field extracts are compared. Phytochemical screening and total amount of alkaloids present in the extracts are obtained. The extracts are subjected to different varying electrical parameters from $1.25 \mathrm{kV} / \mathrm{cm}$ to $3.125 \mathrm{kV} / \mathrm{cm}$. There is $135.12 \%$ increase in alkaloids in PEF treated root extracts with electrical parameters (15 pulses, $100 \mu \mathrm{s}, 3.125 \mathrm{kV} / \mathrm{cm}$ ) than the untreated extracts. Hence, these PEF treated extracts of roots can be used to treat diabetes which helps in lowering the glucose level in the blood.
\end{abstract}

\section{INTRODUCTION}

According to WHO, diabetes is a chronic metabolic disorder that occurs either when the pancreas does not produce enough insulin or when the insulin is not effectively used. Insulin is a hormone that regulates level of blood sugar [1]. Simply, diabetes is caused either by deficiency of insulin or dysfunction [2]. And also it is well known that diabetes leads to micro and macro vascular complications which significantly increases the morbidity and mortality [3] [4]. Almost half of all deaths attributable to high blood glucose occur before 70 years and WHO projects that diabetes will be the seventh leading cause of death in 2030 [5]. Due to its severity and its complications on kidney and vascular diseases, the effect of modern medicines to treat diabetes was not able to effectively cure the disease [6]. Plants are natural antioxidants and effective herbal medicines, due to their anti-diabetic compounds, such as flavonoids, tannins, phenolic, and alkaloids that improve the performance of pancreatic tissues by increasing the insulin secretion or decreasing the intestinal absorption of glucose [7]. Hence there is a need for formulating the crude extracts to use as herbal medicine.

Catharanthusroseus is a well-recognized plant known forits anti-tumor, anti-diabetic, anti-microbial and antimutagenic effects. It produces nearly 130 alkaloids, mainly vincristine, vinblastine, vinceine, vindoline and raubasin [8][9]. Alkaloids exert a widerange of antidiabetic activities through different mechanisms [10]. This plant helps in increasing the insulin production which helps in curing diabetes and also maximum work reported are about the antidiabetic 
potential of this plant by using crude extracts rather than the pure bioactive compounds [11][12]. Fig. 1 shows the chemical structure of Vinca alkaloids. PEFassisted extraction is one of the emerging non-thermal promising technology for enhancing the extraction of bioactive compounds such as polyphenols, lycopene. This involves application of electric pulses which generate a pulsed electric field, produces the formation of pores in the cell membranes of plant tissues enhancing the diffusion of solutes through the cell membranes, favoring the recovery of intracellular substances, including oil and molecules of interest [13][14]. To attain enhanced extraction, PEF is used. This work includes the extraction of alkaloids from Vinca rosea roots by conventional method and pulsed electric field method.
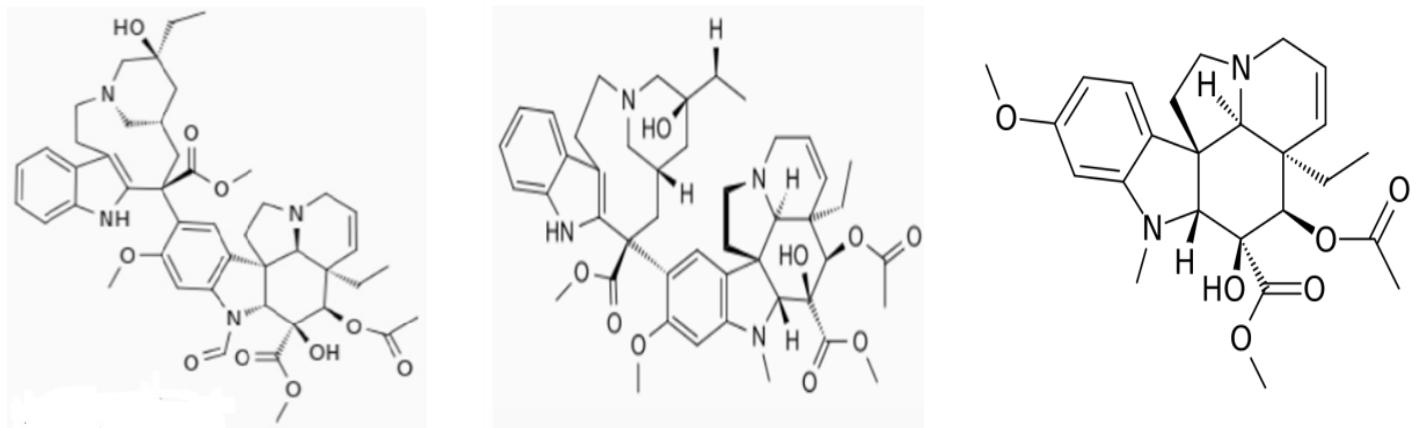

Figure1. Vinca alkaloids - Chemical structure of vincristine, vinblastine and vindoline

\section{MATERIALS AND METHODS}

\section{Collection and Extraction of from Root}

The roots of Vinca rosea are collected from Neyveli, Tamilnadu, India. They were dried in shade and the dried root $(100 \mathrm{gm})$ were powdered by electrical blender. This was loaded in the inner tube of the Soxhlet's apparatus and then fitted into a round bottomed flask containing ethanol as a solvent. The solvents were boiled gently in the temperature range of $80-90^{\circ}$ Cover a heating mantle using the adjustable rheostat. The extraction was continued for 8 hours and the solvent was removed at the reduced pressure with the help of rotary vacuum evaporator to yield a viscous dark residue of ethanol extract. Fig. 2 shows the experimental set-up and the procedure.

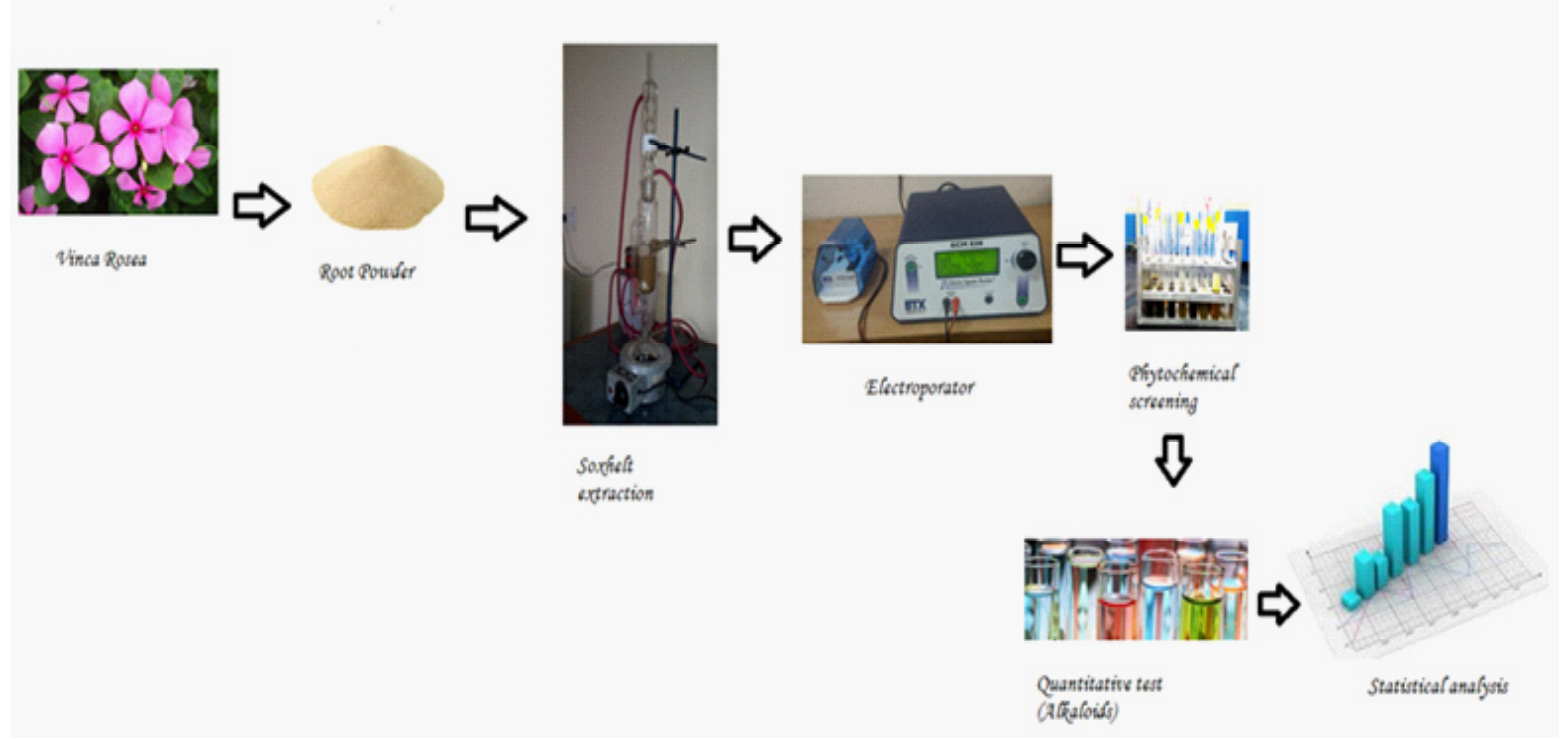

Figure2. Experimental flow: Vinca rosea Flowers and roots are collected and shade dried; Ethanolic extracts are made and are electroporated by using ECM830 Electroporator; Followed by the phytochemical and alkaloids testing; Comparative study for PEF treated and untreated samples are done 
Effect of Pulsed Electric Field on Alkaloids of Vinca rosea Root

\section{Pulsed Electric Field Application}

A BTX ECM 830 Electroporator (High Voltage Laboratory, College of Engineering, Anna University, Chennai) was used to generate unipolar square pulses. The extract is placed in the cuvette chamber (electrode gap $=4 \mathrm{~mm}$ ) which holds $800 \mu \mathrm{l}$ of the sample and the electrical pulses were applied. All the experiments were performed in triplicates. The electrodes are made up of stainless steel and the walls of the cuvette are made up of Teflon (insulation). After applying electrical pulses the Vinca rosea extracts were transferred to separate vials and it has been used for further analysis.

\section{Phytochemical Screening}

\section{Qualitative Analysis of Phytochemicals}

The ethanolic extracts of roots were subjected to preliminary phytochemical screening [15]. Test for alkaloids (Mayer'stest), terpenoids (Salkowski test), Saponin (Froth Test), Polyphenols (Ferric chloride Test), Flavonoids (Ammonia Test), steroids (Acetic Anhydride Test), Tannins (Ferric chloride Test) were done to check the presenceof phyto constituents.

\section{Quantitative Anallysis of Phytochemicals}

Quantitative estimation for amount of alkaloids present in the extracts are done by following the procedure in [16].

\section{Preparation of Reagents}

Standardization of alkaloids includes following process:
$>$ Preparation of stock solution (Atropine Sulphate)

$>$ Preparation of Bromocresol Green

$>$ Preparation of phosphate buffer

Bromocresol green solution was prepared by dissolving $17.45 \mathrm{mg}$ bromocresol green with $0.75 \mathrm{ml}$ of $2 \mathrm{~N} \mathrm{NaOH}$ and $0.25 \mathrm{ml}$ distilled water and the solution was further diluted to $250 \mathrm{ml}$ with distilled water. Phosphate buffer solution ( $\mathrm{pH} 4.7)$ was prepared by adjusting the $\mathrm{pH}$ of $2 \mathrm{M}$ sodium phosphate (17.9 $\mathrm{g} \mathrm{Na}_{2} \mathrm{HPO}_{4}$ in $250 \mathrm{ml}$ distilled water) to 4.7 with 0.2 $\mathrm{M}$ citric acid (10.505 g citric acid in $250 \mathrm{ml}$ distilled water). Atropine standard solution was made by dissolving $0.6 \mathrm{mg}$ atropine in $6 \mathrm{ml}$ of distilled water.

\section{Preparation of Standard Curve}

Accurately measured $0.4,0.6,0.8,1$ and $1.2 \mathrm{ml}$ of Atropine standard solution was transferred to different test tubes. Then $5 \mathrm{ml}$ of $\mathrm{pH} 4.7$ phosphate buffer and $5 \mathrm{ml}$ of BCG solution was taken and the mixture was shaken with extract along with $1,2,3$, and $4 \mathrm{ml}$ of chloroform. These extracts were collected in $10 \mathrm{ml}$ volumetric flask and then diluted to adjust solution with chloroform.

\section{RESULTS AND DiscuSSIONS}

\section{Phytochemical Screening}

The preliminary qualitative phytochemical screening of Vinca rosea flowers and root extracts showed the presence of various phytochemicals which can be attributed to have anti diabetic, antioxidant properties. Table 1 gives the results of qualitative analysis.

Table1. Phytochemical Screening of Vinca rosea

\begin{tabular}{|l|l|l|l|}
\hline \multicolumn{1}{|c|}{$\begin{array}{c}\text { Name of the } \\
\text { Compound }\end{array}$} & \multicolumn{1}{|c|}{ Vincarosea Extract } & \multicolumn{1}{c|}{ Tests } & \\
\cline { 2 - 2 } & \multicolumn{1}{|c|}{ Root } & & \\
\hline Flavonoids & Present & Ammonia solution Test & Yellowish to Brown Orange \\
\hline Saponin & Absent & Froth Test & Frothing \\
\hline Alkaloids & Present & Mayer's Test & Creamy white \\
\hline Polyphenols & Absent & Ferric chloride Test & Bluish Black \\
\hline Steroids & Absent & Acetic anhydride test & Violet to blue \\
\hline Terpenoids & Present & Salkowski Test & Reddish Brown \\
\hline Tannins & Absent & Ferric chloride Test & Blue or Green \\
\hline
\end{tabular}

It can be inferred that the ethanolic extracts of Vinca rosea roots contained alkaloids, flavonoids and terpenoids. When PEF applied samples were tested for phytochemical screening no changes has been observed in PEF treated samples. 


\section{Amount of Alkaloids}

The standard curve for atropine is plotted (Fig. 3) by measuring the absorbance of the complex in chloroform at spectrum of $470 \mathrm{~nm}$ in UVSpectrophotometer (SHIMADZU UV-1600) against the blank prepared as above but without Atropine.

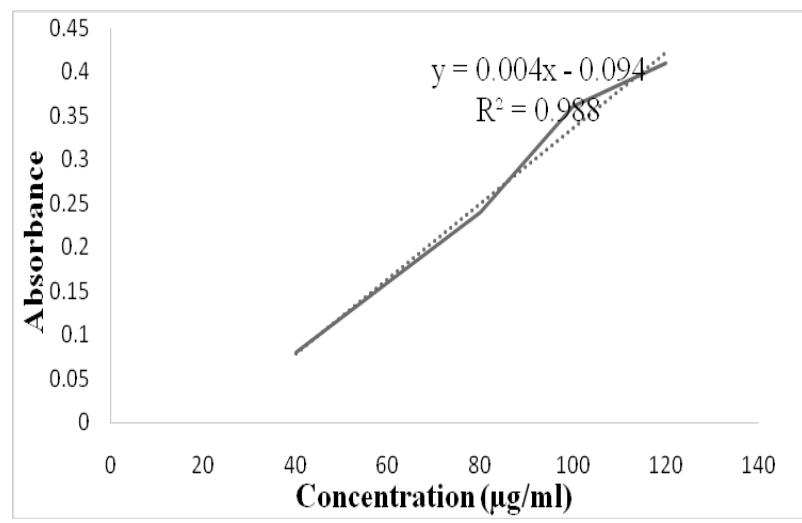

Figure3. Standard curve for Atropine

From this curve the slope equation was calculated as,

$$
y=0.0043 x-0.094
$$

(1)

By using this slope equation the amount of alkaloid extracted in $\mathrm{mg} / \mathrm{ml}$ was calculated, using $\mathrm{y}$ as absorbance calculate $\mathrm{x}$ (where $\mathrm{x}$ is the amount of alkaloid extracted).

Total Amount of Alkaloids in Roots and Flowers of Vinca rosea

Fig. 4 shows the amounts of alkaloid extracted in roots of Vinca rosea for different electric field strengths, varying between $1.25 \mathrm{kV} / \mathrm{cm}$ to $3.125 \mathrm{kV} / \mathrm{cm}$ with same set of number of pulses $(5,10,15)$ applied.

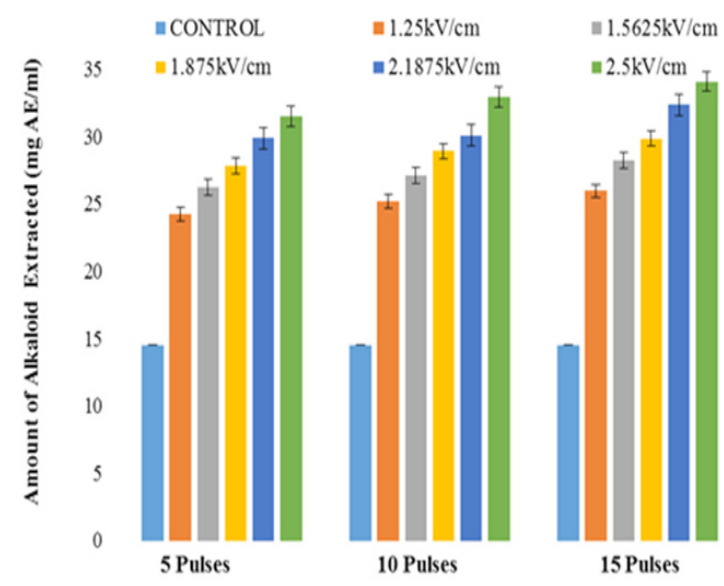

Figure4. Comparison of Vinca rosea roots for different number of pulses for different voltages. Error bars are calculated using standard error
The highest value of cell disintegration is achieved at $2.5 \mathrm{kV} / \mathrm{cm}, 15$ pulses and the amount of alkaloids extracted is 34.48 . When compared to the untreated sample, the maximum percentage increase in the amount of alkaloid extraction is about $135.12 \%$. For $2.5 \mathrm{kV} / \mathrm{cm}, 5$ pulses the amount of alkaloids extracted is found to be $57 \%$ higher than the untreated sample and for $2.5 \mathrm{kV} / \mathrm{cm}, 10$ pulses the amount of alkaloids extracted is found to be $56 \%$ higher than the untreated sample. We could observe that when the voltage exceeds the maximum threshold limit, the amount of alkaloid extracted was drastically reduced when electric field strength of $3.125 \mathrm{kV} / \mathrm{cm}$ is applied for both 10 and 15 number of pulses.

As the number of pulses and electric field strength applied increases, the amount of alkaloid extracted increases significantly. Also, when the voltage exceeds the maximum threshold limit, the amount of alkaloid extracted was drastically reduced when electric field strength of $3.125 \mathrm{kV} / \mathrm{cm}$ is applied for both 10 and 15 number of pulses.

\section{ConCLUSions}

Several plant-based drugs are used to treat diabetes, mainly to reduce the side effects of synthetic drugs. Catharanthusroseus, a herbal plant has high anti diabetic activity, anticancer activity. Different parts of this plant produces different amount of alkaloids. In this work, roots of Vinca rosea plant are extracted by using both conventional and PEF assisted method. Pulsed electric field method has shown to be efficient and effective techniques for extraction of alkaloids in rosea. Results of alkaloids showed that the amount of alkaloids present in PEF treated extract is $135.12 \%$ higher than the normal root extracts. Hence, PEF treated root extracts could be used as a potent source fortreating diabetes.

\section{REFERENCES}

[1] http://www.who.int/news-room/fact-sheets/ detail/diabetes.

[2] Modak M, Dixit P, Londhe J, et.al., "Indian herbs and herbal drugs used for the treatment of diabetes", Journal of Clinical BiochemNutr. 2007; 40(3): 163. doi: 10.3164/jcbn.40.163, PMID: 18398493, PMCID: PMC2275761.

[3] Pyorala K, Laakso M, Uusitupa M, "Diabetes and atherosclerosis: an epidemiologic view", Diabetes Metab Rev. 1987;3:463-524. 
[4] Laakso M, "Hyperglycemia and cardiovascular disease in type 2 diabetes", Diabetes. 1999;48:937-942.

[5] Mathers CD, Loncar D, "Projections of global mortality and burden of disease from 2002 to 2030", PLoS Med, 2006, 3(11):e442.

[6] G. Sumana and S. A. Suryawashi, "Effect of vinca rosea extracts in treatment of alloxan diabetes in male albino rats", Indian Journal of Experimental Biology, vol. 39, pp. 748-758,2001.

[7] WesamKooti, Maryam Farokhipour, Zahra Asadzadeh, Damoon Ashtary-Larky, Majid Asadi-Samani, "The role of medicinal plants in the treatment of diabetes: a systematic review", Volume: 8, Issue: 1, Pages: 1832-1842, DOI: http: //dx.doi.org/10.19082/1832,January 2016.

[8] Puniasandeep, Kaur Jagjit, Kumarraman, "Catharanthusroseus: A medicinal plant with potent anti-tumor properties", Int. Journal. Res. Ayurveda Pharm. 5(6), Nov-Dec 2014.

[9] Maryam Moudi, Rusea Go, "Vinca Alkaloids", International Journal of Preventive Medicine, 4(11), 1231-1235.2013.

[10] Switi B. Gaikwad, G. Krishna Mohan and M. Sandhya Rani, "Phytochemicals for Diabetes Management", Pharmaceutical Crops, 5, (Suppl 1: M2) 11-28.2014.

[11] Nammi S, Boini MK, Lodagala SD, "The juice of fresh leaves of Catharanthusroseus Linn. Reduces blood glucose in normal and alloxan diabetic rabbits", BMC Complement Altern Med: http:// dx.doi.org/10.1186/1472-6882-3-2. 2003.
[12] Gacche RN and Dhole NA, "Profile of aldose reductase inhibition, anticataract and free radical scavenging activity of selected medicinal plants: An attempt to standardise the botanicals for amelioration of diabetes complications", Food ChemToxicol; 49:1806-13.2011.

[13] Arianna Ricci, Giuseppina P. Parpinello, and Andrea Versari, "Recent Advances and Applications of Pulsed Electric Fields (PEF) to Improve Polyphenol Extraction and Color Release during Red Winemaking", http://dx.doi.org/10.3390/ beverages 4010018. 2018.

[14] Nadia Boussetta, Nabil Grimi and Eugène Vorobiev, "Pulsed Electrical Technologies Assisted Polyphenols Extraction from Agricultural Plants and Bioresources: A Review", International Journal of Food Processing Technology, 1-10, 2015.

[15] Ramasamy Thangavelu Narendhirakannan, Jesuthankaraj Grace Nirmala, Arunagiri Caroline, Suneera Lincy, Melda Saj, Divya Durai, "Evaluation of antibacterial, antioxidant and wound healing properties ofseven traditional medicinal plants from India in experimental animals", Asian Pacific Journal of Tropical Biomedicine S1245S1253, 2012.

[16] Manjunath Ajanal, Mahadev B. Gundkalle, and Shradda U. Nayak, "Estimation of total alkaloid in Chitrakadivati by UV-Spectrophotometer", Ancient Science of Life. 2012;31(4):198-201. doi:10.4103/0257-7941.107361.

Citation: S. Poompavai, V. Gowri Sree, Raji Sundararajan. Effect of Pulsed Electric Field on Alkaloids of Vinca rosea Root. Archives of Diabetes and Endocrine System. 2018; 1(2): 04-08.

Copyright: (C) 2018 S. Poompavai, V. Gowri Sree, Raji Sundararajan. This is an open access article distributed under the Creative Commons Attribution License, which permits unrestricted use, distribution, and reproduction in any medium, provided the original work is properly cited. 